\title{
Un caso de renovación periodística en la Argentina de los años sesenta: la revista Primera Plana
}

Miguel Angel Taroncher Padilla*

Resumo - O presente artigo se propóe a analisar a revista semanal Primera Plana, destacando as principais características que converteram este semanário em um projeto periodístico exitoso, bem como sua postura e vinculação com o mundo político argentino na década de 1970.

Abstract - This article analyses the weekly magazine Primera Plana, asking for the main caracteristics which transformed it in a sucessful project. It also trics to show his position and lies to the Argentine political world in the 1970th.

Palavras-chave - Novo Periodismo - Primera Plana - Argentina.

Key words - New Periodism - Primera Plana - Argentine.

* Profesor y Licenciado en Historia, doctorando del Departamento de Historia Contemporánea de la Universidad de Valencia. Investigador del Grupo de Análisis Político y docente del Área Teórico-Metodológica del Departamento de Historia en la Facultad de Humanidades de la Universidad Nacional de Mar del Plata. 


\section{Introducción}

La década del sesenta, si bien presentó un complejo panorama político caracterizado por restricciones electorales, inestabilidad institucional, golpes de estado y violencia tanto estatal como social, fue un período en el que se afirmaron y extendieron innovaciones culturales que tuvieron su origen tanto en el proceso de modernización socio-económico desencadenado a fines de la década del cincuenta conjuntamente con la recepción de influencias materiales, ideológicas y estilísticas provenientes del contexto internacional. El mundo editorial y del periodismo reflejó este poderoso influjo que se potenció y transformó debido a la llegada y difusión de prestigiosas revistas extranjeras.

\section{La política en los sesenta: \\ bloqueo político y democracia restringida}

El derrocamiento del segundo gobierno del presidente Perón en 1955 y la exclusión de la arena electoral, total y posteriormente parcial del partido peronista, se convirtió en la principal causa de la inestabilidad política que afectó a los gobiernos civiles y militares del período 1955-1973. Del golpe de estado del 16 de setiembre de 1955 surge un gobierno militar: "La Revolución Libertadora", que prohíbe todo tipo de participación política del movimiento peronista y que convoca para el 23 de febrero de 1958 elecciones generales con el fin de restaurar la normalidad constitucional. Merced a un pacto electoral con Perón, que le asegura un importante caudal electoral, triunfa en dicha elección el candidato de la Unión Cívica Radical Intransigente, el desarrollista Arturo Frondizi, quien en 1962 evaluando con optimismo las posibilidades electorales de su partido y en cumplimiento del compromiso político adqurido con el líder jusiticialista, levanta parcialmente la proscripción que pesaba sobre el peronismo habilitando su participación en los comicios para gobernadores provinciales que se celebraron el 18 marzo. El triunfo del peronismo en diez de las catorce provincias en juego, incluyendo la de Buenos Aires (pieza clave de la política argentina) determina que, el 28 de marzo de 1962, las Fuerzas Armadas derroquen al presidente. En su reemplazo, accederá a la primera magistratura el vicepresidente provisional del senado, José 
María Guido, quien - en realidad - será la cara civil de un gobierno de neto predominio militar. ${ }^{1}$ Durante su breve mandato (1962-1963) el Ejército se dividirá en dos facciones opuestas: Azules y Colorados ${ }^{2}$ que se enfrentarán en setiembre de 1962 y abril de 1963. La facción Azul resultará vencedora y llevará a su líder, el general Juan Carlos Onganía, al cargo de Comandante en Jefe del Ejército; el prestigio personal obtenido por la victoria de su bando, su carencia de identificación partidaria y la capacidad de restablecer el orden en las filas del Ejército, lo proyectarán como el nuevo hombre fuerte de la Argentina y posible reemplazo de Perón.

En las elecciones nacionales convocadas para el 7 de julio de 1963, de las cuales es marginado el peronismo, triunfará la fórmula de la Unión Cívica Radical del Pueblo, ${ }^{3}$ encabezada por Arturo Umberto Illia y Carlos Perette, quienes resultarán electos como presidente y vicepresidente constitucionales para el período 1963-1969.4 El 12 de Octubre del mismo año se produce el traspaso del mando y Onganía será confirmado en su cargo, pero en 1965 por desavenencias con el las principales decisiones del presidente ${ }^{5}$ renunciará a la comandancia del Ejército. Desde su retiro se convertirá en la figura convocante de una vasta e informal coalición que conformada por diversos actores

1 Para una visión detallada del proceso ver KVATERNIK, Eugenio. Crisis sin salvataje. La crisis político militar de 1962-1963. Buenos Aires: Editorial del Ides, 1987; y del mismo autor, Coalición moderadora, crisis de sucesión y golpe de estado: la sucesión presidencial de 1964. Buenos Aires: Universidad de] Salvador, Facultad de Ciencias Sociales, 1991.

Los Azules propiciaban una salida electoral limitada, mientras que los colorados proyectaban instaurar una dictadura militar. Para un análisis en profunidad de los proyectos y los enfrentamientos consultar POTASH, Robert. El ejército y la politica en la Argentina 1962-1973. De la caida de Frondizi a la restauración peronista. Primera Parte, 1962-1966. Buenos Aires: Sudamericana, 1994; y ROUQUIE, Alain. Poder militar y sociedad política en la Argentina 11. 1943-1973. Buenos Aires: Emecé, 1983. En adelante UCRP.

4 Los votos en blanco, de origen peronista, alcanzaron el $19,2 \%$, esta situación en que parte importante del electorado no puede elegir con total libertad a sus candidatos, es denominada democracia restringida por Rouquié, op. cit., p. 225.

5 La renuncia de Onganía, las relaciones de los jefes azules con el gobierno de Illia y los detalles de la conspiración militar que se aceleran a partir de ese momento son tratados en KVATERNIK, Eugenio. El péndulo cívico militar. La caída de llita. Buenos Aires: Tesis, 1990. 
sociales y políticos ${ }^{6}$ disconformes con las principales lineas de acción del gobierno radical conspirarán para derrocarlo. La coalición golpista presentará a Onganía como el futuro estadista-presidente de un gobierno militar capaz de resolver los principales problemas del período. Una operación político institucional de tal magnitud necesitaba contar con altos niveles de consenso en la opinión pública. Dicho objetivo se logró en gran parte, mediante una exitosa campaña propagandística en diarios, revistas y semanarios de actualidad nacional, de alta circulación en la clase media. La campaña antigubernamental se nutrió y, a la vez, alimentó el generalizado clima de rechazo al sistema de partidos existente en una considerable parte de la población, cansada de sobresaltos institucionales restricciones electorales, inestabilidad política y golpes de estado. Tal iniciativa tenía como principal objetivo aislar al gobierno, mediante el "vaciamiento del campo político", de Ios apoyos de los sectores medios, altos e intelectuales que potenciase el "consenso de terminación" que permitiese construir una "nueva legitimidad" política.

Así, el golpe de estado del 28 de junio de 1966, autodenominado "Revolución Argentina", a semejanza del golpe de 1964 en Brasil, fue

"La "coalición azul", tal como hemos denominado a este heterogéneo conglomerado estaba compuesto por el ejército, sectores nacionalistas, católicos preconciliares, empresarios y financistas, tecnócratas apartidarios de derecha, periodistas, y sindicalistas anticomunistas.

7 Ellos eran: la integración del peronismo, el crecimiento y la eficiencia económica, la seguridad nacional, la inserción en el Occidente Cristiano, la lucha anticomunista, el restablecimiento del orden social, político y el problema fundamental que englobaba al resto: detener la, en apariencia irrefrenable, decadencia argentina.

8 "Cuya consecuencia es el descentramiento del adversario, reducido a una suerte de 'residuo'." SIGAL, Silvia, VERÓN, Eliseo. Perón o Muerte, los fundanentos discursivos del fenómeno peronista. Buenos Aires: Legasa, 1986, p. 233.

"La situación en que los actores sociales y políticos concuerdan en que debe producirse un cambio que establezca nuevas reglas de competición partidarias, en O'DONNELL, Guillermo. Modernización y autoritarismo. Buenos Aires: Paidós, 1972.

10. Durante el gobierno de Illia se da la emergencia de una nueva legitimidad política basada en la ideología tecnocrática de la modernización y la eficacia técnica en contraposición a la tradicional legitimidad electoral, Rouquié, op. cit., p. 245 y ss. Para una mayor precisión sobre el nuevo proyecto institucional ver RODRÍGUEZ, Rodolfo, TARONCHER PADILLA, Migucl Ángel. "Paso a la Scgunda Repúbiica": Universidad, Nacionalismo y la "Revolución Argentina". I Jornadas Internacionales sobre la Reforma. Mar del Plata: Mimeo, 1998. 
el preludio para la posterior instalación de un estado BurocráticoAutoritario. ${ }^{11}$ Luego de ocupar militarmente el país y expulsar a punta de pistola al presidente y a sus acompañanates del despacho en la Casa Rosada, una Junta Revolucionaria se hace cargo provisoriamente del poder; destituye a todas las autoridades electas de la República, anula las instituciones representativas, prohibe la actividad política, disuelve y confisca los bienes de los partidos políticos. La Junta decide autodisolverse luego de ofrecerle la presidencia al General Onganía, sin limitación alguna en el tiempo y con una concentración de poder nunca antes vista. ${ }^{12}$ Éste, una vez en el poder, impuso una rígida censura a ese sofisticado mundo cultural que, mayoritariamente, había apostado por su "candidatura" y que se había desarrollado, no sin contratiempos, a partir de 1955 merced a la vigencia de la libertad de prensa, mínimamente asegurada por la denominada "democracia restringida".

\section{La apertura externa y el mercado de revistas}

Durante el gobierno de Arturo Frondizi (1958-1962), Argentina no sólo transnacionalizó su economía, sino que abandonó - aceleradamente - el aislamiento que habían propiciado, como parte de su política cultural, los dos primeros gobiernos peronsitas. Este proceso de apertura hacia el exterior, luego de 10 años de autarquía cultural, se verificó - entre otros indicadores - a través de un considerable aumento en el consumo de revistas extranjeras y en un "boom" editorial de publicaciones periodísticas. Para entender estas influencias es indispensable referimos a la conformación del mercado de revistas que llegaban a Buenos Aires, principal centro de consumo y distribución nacional. En un principio, éstas comenzaron a venderse sólo en librerías especializadas y para un público restringido, pero más adelante, a finales de los '50 y principios de los ' 60 , se podían conseguir

11 Para una definición de este tipo de estado ver O’DONNELL, Guillermo. $1966-$ 1973. El Estado Burocrático-Autoritario. Triunfo, derrotas y crisis. Buenos Aires: Editorial de Belgrano, 1982, p. 60-61.

12 Junta Revolucionaria: "Mensaje de la Junta Revolucionaria al Pueblo Argentino", "Acta de la Revolución Argentina", "Estatuto de la Rcvolución Argentina" y "Objetivos particulares y generalcs", cn VERBITSKY, Horacio. Medio siglo de proclamas militares. Buenos Aires: Editora/12, 1987, p. 98-110. 
en los kioskos callejeros, de fácil acceso a las compras masivas. Hacia 1966, las revistas extranjeras alcanzaban un volumen de ventas de 5 millones de ejemplares anuales, si bien existían 10 distribuidoras mayores que abastecían 5.500 kioscos (4.000 en Capital Federal y el Gran Buenos Aires, 1.500 en el interior), la mayor parte de las ventas correspondían a la Capital ${ }^{13} \mathrm{y}$, dentro de ésta, a Barrio Norte. También, se destacaba el consumo en las inmediaciones de los hoteles de nivel internacional, a través de los dos importantes kioscos ubicados en las centricas calles y avenidas Diagonal Norte y Corrientes, Santa Fe, Florida, Callao y Alvear. ${ }^{14}$

El consumo de elite estaba conformado por los semanarios femeninos Marie Clarie y Elle mostraban interesantes índices de venta (2.200 ejemplares), al igual que las revistas sobre política Le Nouvel Observateur, L'Express y L'Epoca. Time y Life estaban en el tope (3.500 ejemplares). A ellas le continuaban, con un buen nivel de consumo, L'Europeo, Das Beste y Paris Match. Asimismo, la oferta que intentamos recorrer (aunque no de manera exhaustiva) incluía publicaciones de gran diversidad temática y bajo porcentaje de consumo: Top, Annales, France Dimanche, Moteurs y Batir (francesas), y Bolero Film, Domenica Quiz y Calandrino (italianas). ${ }^{15}$ Tal enumeración de materiales periódicos, que llegaban al país por exclusivo interés de lectores argentinos, indica tanto la presencia y características de un segmento de la sociedad (cosmopolita, sofisticado y curioso, con posibilidades de consumo), con una importante capacidad de recepción de productos culturales extranjeros.

13 En 1963 se vendieron 5.100 .000 revistas y otras publicaciones; en 1964, 5.800 .000 (lo que implicá un aumento del $12 \%$ ). Para 1965 y 1966 se continuó esa tendencia de ascenso. Buenos Aires, la ciudad más informada del mundo, en Confirmado, n. 54, Buenos Aires, 30 de junio de 1966, p. 44-45.

14 El recorte espacial que aquí especificamos no sólo se refiere al lugar de residencia de unas clases sociales media y alta, sino también a sus particulares habitus de clase. En este sentido, poniendo en relación una distribución del espacio y una serie de marcas identificatorias del grupo social que en cada uno de cllos se desenvuelve, el grupo ubicado en cstas calles de la ciudad de Buenos Aires se caracterizaba por su gusto especial por los bienes materiales y simbólicos extranjeros de alto standing, su refinamiento y veleidades intelectuales. (Sobre el concepto de "campo cultural" y "habitus de clase". BOURDIEU, Pierre. Razones prácticas. Sobre la teoría de la acción. Anagrama: Barcelona, 1997.

15 Confirmado, idem. 
Como un caso paradigmático, de la permeabilidad y avidez consumidora, respecto de los prestigiosos productos culturales llegados del exterior podemos reseñar el fenómeno de la revista francesa Planéte, que dirigían Louis Pauwels y Jacques Bergier. Ésta apareció en París en 1962 en forma bimestral, su formato era inusual para la época: papel grueso, alta calidad de impresión, moderna diagramación, un diseño interior que jugaba con las fotografías y el texto. En sus páginas desfilaban, en abigarrada convergencia, las ideas de la nueva derecha europea, la divulgación de acontecimientos científicos, los relatos de horror psicológico de Howard Philip Lovecraft y pesquisas sobre la antigüedad. Su primera edición en Buenos Aires (era su primer tiraje fuera de Francia), a pesar de su alto costo, se convirtió en un best-seller sin precedentes entre los lectores. La primera edición salió en la segunda semana de setiembre de 1964 con una tirada de 12.000 ejemplares que se agotó en 24 horas.

Otro ejemplo de dicha tendencia lo encontramos en el éxito comercial del periódico político uruguayo de izquierda Marcha (con 9.500 ventas semanales de los 11.000 que llegaban los viernes a Buenos Aires); en los 400.000 ejemplares mensuales de comics publicados por editorial Novarro de México y en la variedad de revistas para niños (en castellano) editadas en los Estados Unidos. De igual modo, en el aumento de la industria editorial y de las redes de distribución nacional. A las grandes firmas (Emecé, Losada, Sudamericana) se unieron varias empresas alternativas (Fabril, Centro Editor de América Latina, Jorge Álvarez, De la Flor). Junto con ellas, la editorial de la Universidad de Buenos Aires, EUdEBA, comenzó a imprimir ejemplares baratos de textos clásicos nacionales y extranjeros en grandes tiradas. $^{16}$

16 "EUDEBA se ubicó desde su creación, en una tesitura que buscaba fundamentalmente un óptimo nivel de divulgación y un auéntico redimensionamento del mercado lector, a travćs de coleciones concebidas com un neto enfoque de extensión cultural, producidas a bajo custo y comercializadas a través de distribuición y ventas que rompían com los tradicionales circuitos y tabués del libro ... demonstró en forma concluyente la possibilidad de poducir un libro de óptimo nivel grafico y cultural a bajo precio", RIVERA, Jorge. Eudeba: un esfuerzo editorial inćdito, cn Apogeo y crisis de la industria del libro: 1955-1970. En: Historia de la literatura argentina. Buenos Aires, CEAL, 1981, p. 638. 
Ahora bien, este acelerado ritmo de circulación se veía facilitado por el incremento del poder adquisitivo del salario, por el aumento y consolidación de los índices de alfabetización, la profesionalización y el auge de los medios audiovisuales. Estas eran algunas de las instancias de un proceso de modernización económica y cultural de mayor alcance promovida por el Estado a través de la fundación de instituciones estatales de promoción cultural, educativa y científica como el Consejo Nacional de Investigaciones Científicas y Técnicas, el Instituto Nacional de Tecnología Agropecuaria, el Instituto Nacional de Tecnología Industrial, el Consejo Nacional de Educación Técnica, del Instituto Nacional de Cinematografía y del Fondo Nacional de las Artes. En el ámbio de la educación superior el incremento del presupuesto para infraestructura e investigación en las universidades, junto con las condiciones que brindaba la desperonización de los claustros, la vigencia de la autonomía universitaria y el gobierno tripartito, permite un proceso de renovación teórica y metodologica, funcional a la modernización socieconómica, en el variado campo académicodisciplinar de la Universidad de Buenos Aires. ${ }^{17}$

Se trataba, entonces, del complejo movimiento que interrelacionaba una industria cultural floreciente y una nueva sensibilidad urbana representada por un público básicamente constituído por argentinos de edad y clase medias que se caracterizaba por el deseo casi obsesivo de obtener información actualizada sobre el acontecer nacional e internacional: política, economía, modas, farándula, libros y tendencias plásticas de avanzada. Las apetencias cosmopolitas de este gusto se basaban en la difusa angustia generada por la sensación de quedar al margen de los movimientos culturales de las élites europeas y neoyorkinas, dicha perspectiva existencial le otorgaba un alto valor simbólico al hecho de "estar bien informado", actitud que les permitía sentirse parte - aunque solo fuese a través del consumo - del circuito internacional, que junto con el conocimiento de la oferta informativa y cultural nacional funcionaba como marca de un elevado status inte-

17 Un caso paradigmático de este proceso es el caso de Gino Germani en Facultad de Filosofía y Letras, donde surge y se potencia la sociología "científica" funcionalista. Ver GERMANI, Gino. La sociología en Argentina. Revista Latinoaméricana de Sociología. 68-3, v. 4, Instituto Di Tella, Buenos Aires: Instituto DiTella, v. 4, n. 68, 1968 y NEIBURG, Federico. Los intelectuales y la invención del peronismo. Buenos Aires: Alianza, 1998. 
lectual y social. ${ }^{18}$ Este segmento consumidor en definitiva, una amplia oferta informativa para una clase media ajustada a un orden diferencial de participación pública - social e individual - y a las nuevas formas de administración del tiempo libre y ocio recreativo. Este sector social -ávido consumidor de bienes simbólicos y culturales que asistía con frecuencia al cine, a conciertos, teatros, exposiciones de pintura, escultura y asumía, además, el psicoanálisis como práctica cotidiana, ${ }^{19}$ necesitaba estar "bien informado" y "a la page" en sus circuitos profesionales y ámbitos de sociabilidad, ${ }^{20}$ que requerían además de la información general una guía y árbitro que guiara sus gustos y preferencias por los sinuosos senderos de las cambiantes modas y fuese, a la vez, un objeto, un artefacto de distinción. En este fértil campo de experimentación estética e informativa y para responder a estas demandas surgirá y se consolidará Primera Plana.

18 Benedict Anderson propone el carácter imaginario - es decir, las marcas simbólicas y culturales que justifican y certifican el trazado de fronteras ćtnicas y nacionales, pero también socio-económicas - de los vínculos de identidad y las formas excluyentes de la diferencia. ANDERSON, Benedict. Comunidades imaginadas. Reflexiones sobre el origen y la difusión del nacionalismo. México: Fondo de Cultura Económica, México, 1997, p. 26 y ss.

19 Para la historia del psicoanálisis en la Argentina y particularmente en la década del sesenta, ver BALÁN, Jorge. Cuéntame de tu vida. Una biografía colectiva del psicoanálisis colectivo. Buenos Aires: Planeta, 1991, p. 141-172

Cuando hablamos de este tipo de insumos, espacios y consumidores, es imposible soslayar un ámbito de convergencia: el Instituto Di Tella. Éste, junto con la Fundación, nació el 22 de julio de 1958 a instancias de los hermanos Guido y Torcuato Di Tella para canalizar fondos privados hacia las actividades culturales y sociales según el modelo de fundación norteamericano de financiación corporativa. La fundación de la que formaban parte la familia Di Tella, dueña de una fábrica de automotores y electrodomésticos, junto con subsidios de las fundaciones Ford y Rockefeller proporcionarían los fondos para el funcionamiento del Instituto. Se proponía trabajar como una institución de investigación autonóma en el campo de las ciencias sociales y las artes. Su actividad incial rondó alrededor de la plástica, después incorporó las ciencias sociales, el teatro y la música, a traves de centros donde se desarollaría uno de los movimientos culturales más importantes y exitosos de la década del sesenta. "La moda 'hippie' fue identificada con las cuadros que rodeaban al Di Tella y la zona se llegó a conocer como la 'manzana loca' a causa de sus boutiques, bares y el Instituto mismo [...], un lugar donde se exhibían las últimas tendencias. En las cercanías, la plaza San Martín y más tarde la feria artesanal de la plaza Francia fueron cada vez más asociadas con lo que en Argentina sc ha llamado sin mayor rigor 'cultura hippie', sin mayor rigor porque el término se aplicaba a cualquiera que tuviera pelo largo, barba, abalorios, guitarras y ropas diferentes". ROMERO BREST, Jorge. Arte visual en el Di Tella. Aventura memorable en los años '60. Buenos Aires: Emecé, 1992, p. 9 


\section{Primera Plana: una necesidad editorial, un proyecto político}

Como revista de información general, Primera Plana surgió en un mercado editorial y simbólico como el descripto, a partir de la propuesta que militares del victorioso bando Azul - deseosos de crear un órgano "novedoso", "moderno" y "atractivo" para la "convincente" difusión de su proyecto político - le hicieran a Jacobo Timerman quien en 1962 fundó Primera Plana con el capital que le solicitó a un empresario amigo. El semanario, en un principio se llamaría Azul, sin embargo, para darle un carácter entre imparcial y más abarcante que el que sugería el nombre de una facción del Ejército se optó por el más "actual" y "protagonista" de Primera Plana. Luego, en base a la fórmula exitosa expermientada en Primera Plana, Timerman pasará a dirigir durante los sesenta una revista competidora: Confirmado y en la primera mitad de los años setenta, el prestigioso diario La Opinión. Dentro del periodismo argentino, Tímmerman, ganador del premio Pullitzer, es considerado una de sus más brillantes personalidades. ${ }^{21} \mathrm{Si}$ bien participó de la extendida cultura política que consideraba a los golpes de estado como instancias de resolución de la problemática nacional; en 1976, producido el derrocamiento de Isabel Perón, será secuestrado y torturado por la nueva dictadura militar, el Proceso de Reorganización Nacional que, mediante un Acta Institucional, lo despojó de la ciudadanía argentina e intervendría y confiscaría su diario.

Con su estilo y dinámica particulares, Primera Plana buscaba romper con las formas "pesadas, históricas y literarias" del contexto en el que aparecía y, al tiempo, crear una imagen "renovadora" para el proyecto de modernización que los factores de poder proponían como alternativa a la gestión de los partidos políticos tradicionales: " $L a$ Nación y La Prensa (la primera, crónica formativa, novela patria y autoridad del patriciado; la segunda, auto-elogio de la profesión liberal del periodista-político), La Razón (sub-producto del iluminismo de un sector conservador subalterno y de la burocracia oscura e inferior del Estado) [...] y Clarín (alusión a un instrumento musical que llama al lector de un modo desarrollista, con pífanos codificados y optimistas para significar un confiante despertar de las nuevas fuerzas vivas

21 Para una versión más amplia de su trayectoria en el periodismo argentino, consultar ULAVNOSKY, Carlos. Paren las rotativas. Historia de los grandes diarios, revistas y periodistas argentinos. Buenos Aires: Espasa, 1997. 
del país)". ${ }^{22}$ Esto no significa que la prensa argentina no hubiera sufrido transformaciones previas ya en los años '30. El popular diario Crítica había sorprendido al público argentino, ${ }^{23}$ en este sentido, ambos proyectos editoriales compartieron un característica definitoria: un equipo periodístico capaz de construir la noticia con un estilo propio.

Para lograr su objetivo, se diseñó en función de los modelos de tratamiento informativo que proponían los cosmopolitas semanarios Time y Newsweek, Der Spiegel y L'Express y los diarios Le Monde y The New York Times; Timerman con experiencia en equipos de redacción supo conformar un brillante equipo de jóvenes y destacados periodistas $^{24}$ entre los que sobresalían Tomás Eloy Martínez, Ramiro Casasbellas, Osiris Troiani, Ernesto Schoó, Roberto Aizcorbe, Hugo Gambini; quienes con posterioridad tuvieron destacada actuación en el mundo del periodismo y la cultura. Este nuevo emprendimiento editorial se integró y a la vez fue producto del entramado cultural constituido por la “...experiencia del Di Tella, el auge de la novelística política latinoamericana, $[\ldots]$ el estructuralismo y la semiología de Roland Barthes". ${ }^{25}$ De esta manera, el estilo de Primera Plana absorbió las tendencias formales europeas y norteamericanas a la vez que reflejó periodísticamente el mundo de las transformaciones económicas, sociales y políticas que vivía el país durante los ' 60 , reproduciendo los valores y actitudes de la clase media urbana y fudamentalmente porteña, ${ }^{26}$ a quien develaba saberes e informaciones ocultas a la vez

22 GONZÁLEZ, Horacio. La realidad satírica. Doce hipótesis sobre Página/12. Buenos Aires, s.d, p. 13-14.

23 SAÍTA, Sylvia. Regueros de tinta. El diario Crítica en la década de 1920. Buenos Aires: Sudamericana, 1998.

24 Las características de este equipo era reconocido por los lectores de la revista, tal es el caso de una Carta donde el político opsitor paraguayo Osvaldo Chaves envía al director quejándose del trato benévolo que los periodistas habían tenido para con la dictadura de Stroessner. "Nubiérmos querido que sus redactores - los más capaces que tiene hoy por hoy América Latina, en revistas de este tipo - dirigieran al 'envés de la trama' [...]", en Primera Plana, n. 162, 14 de diciembre de 1965, p. 79.

25 Ibid.

26. Para el problema que nos ocupa resulta de gran utilidad la idea de una retroalimentación de los imaginarios sociales entre los medios de comunicación masiva y el público lector, según la cual: "En y por la propaganda moderna, la información estimula la imaginación social y los imaginarios estimulan la información, y todos 
que investía y distribuía prestigios. Así, al mismo tiempo que se hacia eco de las necesidades del mundo económico mediante un discurso que enfatizaba la necesidad de una mayor racionalidad y eficiencia para potenciar la actividad industrial que se revelaba a través de sus notas y columnas sobre economía y gestión empresarial, ofrecía una guía de la moda en sus diversas manifestaciones: desde libros y música (de los cuales se publicaba listas de los mas vendidos), cine, ${ }^{27}$ arte y ropa, a un suplemento que posteriormente pasará a ser una sección fija, dedicado exclusivamente a la mujer: Primera Dama. En "Extravagario" indicador de las tendencias de la moda figuraban, todo tipo de lugares y actividades dedicadas al ocio y eventos culturales, donde la presencia de las actividades del Instituto Di Tella y sus artistas eran permanentes.

Desde la impronta de un nombre que remite a la noción misma de periodismo (focalización o encuadre de la noticia en un "primer plano") y la elaboración de las tapas (que funcionan como un espacio simbólico de legitimaciones y exclusiones), Primera Plana se (auto)presentaba como rectora de un "saber vivir" urbano, de un "saber hacer" cultural y de un "deber ser" nacional el que se concebía integrado a un "primer mundo" desarrollado, exitoso y eficiente, un mundo tal como lo querían y proponían las principales empresas multinacionales, la banca y el mundo de los negocios argentinos que anunciaban en sus páginas. ${ }^{28}$ Sobre el fondo ecléctico y siempre novedoso del diseño de la portada, que podía ser un dibujo, una foto, una fotocomposición o una caricatura, destacaba en letras negras el nombre de la revista, Primera Plana, y su rótulo identificatorio: "La revista de noticias de mayor circulación". Particularizada por el artículo

juntos, estos fenómenos se contaminan unos con otros en una amalgama extremadamente activa, a través de la cual se ejerce el poder simbólico". BACZKO, Bronislaw. Los imaginarios sociales. Memorias y esperanzas colectivas. Buenos Aires: Nueva Visión, 1991, p. 30.

27 Fenómeno que merece ser resaltado por su impacto socio-cultural es el cine de Bergman, proyectado generalmente en el cine "Lorraine" en salas que se llenaban. El director sueco reconoció en el público argentino a uno de sus más fieles seguidores en el extranjero. Sus películas, como toda la producción cinematográfica de vanguardia, merecían un tratamiento especial por parte de la revista. El estreno de "El Silencio" fue recomendada por la "Carta al Lector" y se le dedicó un informe especial de tres páginas. Primera Plana, n. 66, 11 de febrero de 1964, p. 3.

28 Banco Tornquist, Siam, Fiat, Kaiser, ITT, Pirelli, Kodak, Richmond Tobacco, IBM, Ford, Grundig, Olivetti, Roche, Esso, Grafa, Alitalia, Ipako. 
definido "la" y autocertificada por la aceptación masiva "de mayor circulación", ${ }^{29}$ la portada exhibía pintores, músicos, artistas, escritores latinoamericanos ${ }^{30} \mathrm{y} \operatorname{argentinos}^{31}$ (a quienes se propuso especialmente promocionar conformando de esta manera el "boom" literario de los sesenta ${ }^{32}$, personajes públicos y temáticas relevantes de actualidad y políticos "ineficientes" o "modélicos" de la época. En el primer número, del 7 de noviembre de 1962, por ejemplo, en forma conjunta, como definición editorial y en una operación simbólica de identificación apareció el rostro del presidente Kennedy, político joven, dinámico y exitoso, propulsor de una nueva imagen del capitalismo, del anticomunismo y de la modernidad: emblema que pretendía encarnar la revista. De igual modo, fueron muchos los números en los que apareció en sus tapas o en sus páginas interiores el presidente Illia ridiculizado - el humor gráfico en uso de las libertades públicas nunca había llegado tan lejos como hasta ese entonces - por el trazo defor-

29 "En los primeros meses de existencia Primera Plana ya había alcanzado un promedio de 25.000 cjemplares. Esa cifra creció significativamente, a medida que se acercaba el golpe de Estado junio de 1966, hasta alcanzar un promedio semestral de 50.000 cjemplares. Las semanas posteriores al cuartelazo marcaron un pico histórico de 58.000 ejemplares que solo se repetirian tras el mayo francés de 1968, y serian superados en los covusionados meses que siguieron al Cordobazo". MAZZEI, Daniel. Medios de Comunicación y golpismo. El derrocamiento de Illia (1966). Buenos Aires: Grupo Editor Universitario, 1997, p. 92.

31) Aparecieron aquí los primeros reportajes a Gabriel García Márquez, José Donoso, Juan Carlos Onetti, Octavio Paz, Salvador Garmendia, Carlos Fuentes y Mario Vargas Llosa.

31 Entre sus páginas había artículos y cuentos de Julio Cortázar. Se rescató la figura de Leopoldo Marechal y se promocionó a las figuras emergentes o no los suficientemente difundidas de Norma Leandro, Alfredo Alcon, Juan Carlos Paz, Emilio Petorutti.

"Los nuevos semanarios, [...], fueron la punta de lanza de un nuevo y agresivo concepto promocional y comunicacional, que superó la parquedad de las clásicas gacetillas bibliográficas, o la sesuda monotonía monográfica de la crítica tradicional, mediante una incisiva y bien preparada batería de reportajes, comentarios, notas, gacctillas biografías, polémicas, noticias y variedades que creaban el clima propicio para el lanzamiento de un libro e inclusive de todo un fenómeno literario. Por primera vez en la historia de las letras argentinas el escritor era objeto de un cuidado y de una atención tan prolijos en un medio periodísitico no específicamente cultural o especializado, y también por vez primera se les dedicaban portadas, o se los invitaba a participar en programas radiales y televisivos con el objcio de conocer sus ideas sobre cuestiones pertinentes o totalmente impertinentes". Rivera, op. cil., p. 638-639. 
mante de las caricaturas de Flax, seudónimo del dibujante Lino Palacio, quien lo representaba como un anciano inútil y lento, ${ }^{33}$ como un títere del presidente de la UCRP, Ricardo Balbín, o como un gobernante que no alcanzaba a comprender la gravedad de los males que aquejaban a la República, ${ }^{34}$ en contraposición, más de una entrega presentó la fotografía dignificante y adusta de Onganía. A través del humor, en la medida en que se recreaban y ridiculizaban situaciones del acontecer político, se informaba y a la vez se valoraba el suceso. De esta forma, el humor quebraba la rigidez informativa del texto y funcionaba, al mismo tiempo, como un efectivo y ácido resumen de las secciones a las que acompaña. El toque humorístico estaba siempre presente, en las sección de política nacional las caricaturas de Flax y las series de notas de Jordán de la Cazuela, "Paralipómenos" y en las del panorama internacional la columna de Art Buchwald, "Entretelones". En sus páginas apareció por primera vez la célebre "Mafalda" de Quino que luego de unos pocos meses, pasó a un periódico y después a una revista de actualidad. El quiebre de la tradicional rigidez del texto periodístico, se lograba de igual manera a través de la conjunción entre el discurso escrito y las ilustraciones de los dibujantes Kalondi y las vińetas de Miguel Brasco.

33 En el $N^{\circ} 164$, del 28 de diciembre de 1965 , la portada fue una caricatura de Flax que presentaba al presidente como un anciano de rostro ajado y cansino, encorvado, con una paloma en su cabeza con un cuchillo en la mano y a punto de cortar un pan dulce, esta imagen que se acompañaba del siguiente epígrafe". ¿Y si les digo que tampoco sé como se corta un pan dulce?". En una viñeta del mismo autor el presidente aparecía como una tortuga diciendo: "¿Qué apuro hay?", a lo que la revista agregaba que el autor "concibió de este modo, la semana pasada, la imagen que el gobierno despierta en la opinión pública. La figura del presidente Illia identificado con una tortuga, parece haberse impuesto, con diferentes matices, en el espíritu de los caricaturistas argentinos", Primera Plana, n. 175, 3 de mayo de 1966 , p. 8.

34 En la sección "El País", cl relato reitcraba el concepto propuesto por la imagen visual retroalimentándose en una mutua interacción: "Para Arturo Illia, la cita convenida con el Presidente de Chile, Eduatdo Frei, resultó providencial. De otra manera, habría tenido que seguir con sus giras por el interior, con sus anodinas charlas entre paisanos, para eludir e] teatro de los acontecimientos [...]. Porque, ya se sabe, para Illia no pasa nada grave en la Argentina, apenas unas escaramuzas entre agitadores, y la mejor manera de demostrarlo es ausentarse, viajar plácidamente, trasladar su imagen entre cansina y patriarcal, hacia latitudes más crédulas". "Politica: la nueva situación", Primera Plana, 2 de noviembre de 1965, p. 8. 
La primera columna que presentaba a la revista, la "Carta al lector", era una propuesta que invertía el tradicional espacio de las cartas que el lector envía al director para expresar sus opiniones operando, en este caso, como un direccionado mapa de lectura. En ella se establecía una jerarquización de los temas que no sólo funcionaba como una tabla de contenidos, sino que focalizaba - como hacen las tiendas de modas al armar sus escaparates - lo "mejor" que tenía la revista en función de la totalidad de cada número. En un giro de simultáneas autopublicidad, legitimación y prestigio, esta columna manifestaba, por un lado su preocupación por insertarse y mostrar el mundo internacional, del cual ella misma se postulaba como un vínculo, ${ }^{35}$ destacando en forma permanente la referencialidad nacional ${ }^{36}$ y por otro caracterizaba al lector implícito como "un público del más alto nivel intelectual", ${ }^{37}$ de considerable poder adquisitivo "de entre las $250 \mathrm{mil}$ personas que todas las semanas leen Primera Plana [...], más de la mitad está preparando un viaje de importancia, la mayoría al exterior, por negocios o placer. De aquel total, la tercera parte ha viajado ya al exterior una o más veces; un alto porcentaje toma todos los años sus vacaciones en el extranjero". ${ }^{38}$ Para ellos, para "guiar" a esos argentinos "inquietos" y tan cosmpolitas como la revista pretendía serlo, deseosos de recorrer y descubrir el mundo, se les preparó un informe especial. $^{39}$

En sus páginas se hace perceptible el interés por construir un espacio editorial diferenciado de la producción periodística tradicional, para un público también diferente. Este aspecto se pone de manifiesto cuando Jacobo Timerman, define lo que es el "antiguo" periodismo frente al enfoque que ofrece Primera Plana: "Antiguamente se creía

35 En su oferta de suscripción para el extranjero la revista se autopostulaba como que "ES El hilo Que une LA ARgentina Con el mundo", Primera Plana, n. 208, 20 de diciembre de 1966, p. 39.

"Esta búsqueda de las grandes noticias en sus propias fuentes es una costumbre que el propio Casasbellas [subdirector] confirmó un año atrás, cuando se supo que John F. Kennedy había sido asesinado en Dallas y que la única manera de saber exactamente qué había pasado era volar a la ciudad de la tragedia. Desde entonces Primera Plana no cesó de informar a sus lectores sobre cada agitación del mundo, pero con su propia mirada argentina", Primera Plana, n. 104, 3 de noviembre de 1964 , p. 3.

37 Carta al lector, Primera Plana, n. 169, 22 de marzo de 1966, p. 3. 
que el periodismo cumplía con su misión si se limitaba a informar qué pasó, cuando, cómo, dónde y quién lo hizo. Nosotros hemos insistido en la idea de que, a esas cinco preguntas básicas, es ahora necesario agregar otras dos: por qué sucedió lo que sucedió, y para que sirve. A estas dos preguntas no es posible, ya, responder de una manera aisla$\mathrm{da}$, tomando los hechos uno por uno; para contestarlas hay que vincular un suceso con otro, armar un esquema coherente de la realidad $y$, en fin explicar, llegar al trasfondo, que es lo que procuramos hacer en todas nuestras secciones." "Esta operación de distinción le permite ajustarse a los aires internacionales de la época, aires que soplaban desde el norte, de la siempre innovadora capital-símbolo francesa o desde esa especie de Roma imperial contemporánea en la que se convirtió Nueva York a mediados de este siglo.

En cuanto al tratamiento informativo, una de las principales transformaciones surgía de la "contaminación" entre el discurso periodístico y "el discurso literario" " de esta forma las tradicionales formas del primero, la crónica desnuda e impersonal de los hechos, comienzan a privilegiar el relato. Dicha renovación discursiva apelaba a la ficcionalización, al lenguaje metafórico, relatos íntimos, ${ }^{42}$ a la descripción de rasgos personales de los personajes públicos, ${ }^{43}$ encabe-

4n Carta al lector, Primera Plana, n. 84, 16 de junio de 1964, p. 3.

4) ALVARADO, Maite, ROCCO-CUZZI, Renata. 'Primera Plana': el nuevo discurso periodístico de la década del '60. Punto de Vista. Buenos Aires, n. 22, diciembre de 1984, p. 29

42 "Apurate de una vez, cacaré la voz. Él entornó los párpados, casi pegó la nariz contra el vidirio y sonrió. Vamos a llegar tarde. ¿Te fijaste la hora en que va la primera película? Fuc levantando el mentón, sin dejar de acariciarlo con duluzura. Qué macanudo, no había necesidad de afeitarse. ¿O es qué de vuelta pensás llevarme a ese cine en que dan una sola?

"Recién entonces, en la paz de su casa de Villa Urquiza, el 25 de mayo de 1959, frente al espejo del ropero, el scñor Simón Ermach, de 61 años, empezó a hacerse la corbata. Levantó diestramente una punta y la pasó por el nudo. Luego tiró. 'Sí, dijo al fin. 'Todavía tenemos tiempo'. En ese instante, se abrió la rampa del destino y Simón Ermach se precipitó en la nada". Los hombres del corazón a pila, Cirujía, Primera Plana, n. 128, 20 de abril de 1965 , p. 33.

43 "Los rabos de la política: Era una treintena de hombres-sandwich, con letreros del Plan de Lucha de la cGT. Lanzaban volantes, vitoreaban un nombre. El escuadrón de Granaderos tropezó con ellos en plena calle Florida, bajo el nublado mediodía del viernes pasado. Un caballo se encabritó, los soldados cargaron sable en mano contra Jos manifestantes. Después de la sorpresa, quedaron un tendal de cartelones en el pavimento y 24 detenidos en Ia comisaria". "El País". Primera Plana, n. 95, $1^{\circ}$ de sctiembre de 1964, p. 7. 
zando las notas en forma no convencional, con títulos de obras o citas de clásicos ${ }^{44}$ o con frases de los personajes protagonistas, para pintar un perfil o demostrar una situación. ${ }^{45}$ Muchos de estos recursos tomados del "New Periodism" generaban una dinámica informativa ágil, informal e intimista entre la prensa y el lector, que, inmerso en una sintonía recíproca se dejaba seducir por lo que Primera Plana le proponía como "su" verdad, en un cruce entre literatura y periodismo. ${ }^{47}$ Es decir, elementos todos que trascendían el hecho inmediato del "dato", donde el proceso comunicativo adquiere un carácter elaborado. De esta manera, la noticia no sólo es el "hecho" sino que forma parte de una aventura del lenguaje, que adquiría las formas de un producto artístico.

En efecto, la revista se presentaba como innovadora, tanto en el tipo y formato de información contenida entre sus páginas, en las temáticas tratadas y en las formas de abordarlas, conjugando la tradición aportada por el periodismo periódico y la innovación que introducían los exitosos semanarios extranjeros. En este aspecto, destacaban la indagación en la vida interna de los partidos políticos, la actitud de permanente diálogo con sus líderes, los panoramas de actuali-

44 "Pcronismo. El telar de Penćlope". La nota comienza con una cita de Apollinaire en francés: "Ulisse que des jours pour rentrer dans Ithaque". Idem. "Políticos Espcrando a Godot", El Pais, n. 208, op. cit., p. 19.

"El holandés errante.

"- Che, Gardel, ¿Qué hacemos?. Vandor respondió: 'Ahora, hay que quedarse piola'. Era la noche del $1^{\circ}$ de febrero, en la puerta de la Unió Obrero Metalúrgica, cuando ya se conocía la carta condenatoria de Perón". "El País", Primera Plana, n. 167,8 de marzo de 1966, p. 14.

46 "El género de la novela periodística, armazón fundamental del New Periodism, creaba la ilusión de realidad a través de una abrupta incorporación de lenguajes extraídos de las voces cotidianas habladas. Eran testimonios 'arrancados a los personajes' iraspuestos a la narración sin que la subjetividad del escritor se hiciera presente. Esta ilusión de objetividad colocaba la ficción sobre un bastidor muy semejante a la investigación de campo del antropólogo o del sociólogo urbano" (González, op. cit., p. 37).

47 Este aspecto es observable, a través de su estrategia de expansión, en una nota que publica la dirección con el título de ¿Es demasiado?, "Primera Plana no sólo hará llegar más enviados especiales a más lugares del mundo, y con mayor frecuencia, sino que también establece en París una corresponsalía que se irradiará por toda Europa, y a cuyo frente está uno de los mayores novelistas latinoamericanos, Mario Vargas Llosa, autor de la ciudad y los perros, para quien el periodismo es ya una antigua profesión.”. Primera Plana, n. 128, op. cit., p. 55. 
dad nacional e internacional, el trazado de previsiones sobre el futuro, la investigación periodística de informaciones ocultas, exóticas o desconocidas, el seguimiento constante e intenso del quehacer militar, político y sindical, la investigación histórica, ${ }^{4}$ científica y la emisión de comentarios y opiniones sobre la noticia "desnuda". Al mismo tiempo, incorporaba otro tipo de materiales informativos, a través de columnas especializadas permanentes o a término, como espacios cedidos a determinadas áreas específicas del saber: Medicina (a cargo de Florencio Escardó), Psicología (Enrique Pichón Riviere) y Sociología (disciplina redefinida y potenciada en la Universidad de Buenos Aires por el sociólogo Gino Germani, quien publicaba avances de sus investigaciones como exclusivas para Primera Plana).

De acuerdo con los nuevos saberes de funcionamiento determinados por la modernización económica y necesarios para el nuevo tipo de empresario jóven, dinámico y actualizado, que, comenzaba a afianzarse en Argentina - que es parte del público consumidor de la revista - se inserta en el mundo de los negocios a través de una estrategia de redacción que proporciona información jurídica, gerencial, económica y empresaria. En el $N^{\circ} 95$ se incorpora la columna a término de Enrique Aftalión, ${ }^{49}$ que en seis colaboraciones trataría temas de Derecho Económico - considerado como el problema "de mayor interés en nuestro tiempo". ${ }^{50}$ En el $\mathrm{N}^{\circ} 128$ se incorpora como columnista Guillermo S. Edelberg ${ }^{51}$ quien desarrolló, en la sección de "Economía", aspectos sobre Administración de Empresas. Ésta se complementaba, desde ese mismo número, con la columna denominada "Tendencias",

48 El periodista Hugo Gambini coordinará un equipo de investigadores quienes scran los responsables de la aparición semanal de una historia del peronismo.

Legitimado y reconocido especialista en Filosofía del Derecho. Autor de varios manuales para estudiantes universitarios, entre los cuales se encontraba la insoslayable Introducción al derecho, que para el momento contaba ya con 7 ediciones.

50 "Carta al lector", Primera Plana, n. 95, 1 de septiembre de 1964, p. 3

51 Figura modélica de la imagen que promocionaba la revista, este joven y triunfador argentino de 36 años de edad era ingeniero industrial en Buenos Aires y se había graduado dos veces en EEUu como Master of Bussines Administration, en California y Harvard. Hasta 1964 había sido director del Centro de Investigaciones Económicas en el Instituto Di Tella, y en ese momento era también director de la División de Investigaciones del Instituto para el Desarrollo de Ejecutivos en la Argentina. Además, era Titular de Administración de Empresas de la Universidad Católica Argentina. 
donde se desarrollaban desde noticias referidas al funcionamiento de la economía nacional y mundial hasta teorías y sugerencias de economistas internacionales.

Además, en función de una movilidad de columnistas y una permanente expansión de sus secciones se incorporaba dos espacios para la información política nacional e internacional. Por una parte, la denominada "Provincias", permitía ofrecer noticias de todo el territorio argentino por medio de su asociación con diarios del interior, que generaba una red de doscientos corresponsales permanentes que cubrían y reseñaban los acontecimientos "más importantes" del acontecer nacional que ocurrían fuera de la ciudad de Buenos Aires. Por otra, la sección "América y el Mundo", presentaba la realidad internacional desde una "mirada argentina". ${ }^{52}$ En ella se valorizaba la intermediación de la noticia vista por ojos nacionales y captada in situ: se proponía la figura de un periodista testigo, quien indagaba las grandes noticias en el escenario mismo de los acontecimientos. Más adelante, la revista separó "América" de "El Mundo", con lo cual intentaba darle al acontecer de América Latina un lugar autónomo y equivalente al del resto del mundo. Esta actitud frente a los acontecimientos consolidó una tradición reciente en el periodismo nacional: la de enviar a periodistas a cubrir sucesos, seguir procesos y entrevistar a personajes y protagonistas de la actualidad. ${ }^{53}$ Igualmente, incorporó la figura de los corresponsales extranjeros ${ }^{54}$ que convivirían con las notas aportadas por contrataciones específicas con revistas extranjeras. ${ }^{55}$

52 Primera Plana, n. 104, 3 de noviembre de 1964, p. 3.

53 "Y con la ya clásica presencia e sus enviados especiales a cualquier escenario del mundo, cada vez que un gran acontecimiento lo exigía: desde el asesinato de Kennedy, cuyas consecuencias investigó, en Dallas y Washintgon, Ramiro de Casasbellas; o el pimer viaje de un Papa, desde San Pedro a las tierras de Jesús, descripto por Tomás Eloy Martínez; o la Conferencia Mundial de Comercio y Desarrollo, en Ginebra, seguida por Julián Delgado, hasta los Juegos Olímpicos de Tokio, que narró Ernesto Schóó, y el viaje sudamericano del general de Gaulle, a quien acompañó Osiris Troianai en todas la capitales de este continente." ¿Es demasiado? Primera Plana, n. 128, op. cit., p. 55.

54 Mario Vargas Llosa (París), Armando R. Puente (Madrid), Alberto Giovaninni (Roma), Curt Donig (Berlin Occidental) y Edmundo Rovira (Montevideo).

55 En el n. 169 se expone la inclusión esta modalidad ' $L$ ' Express aporta entretelones y datos decisivos para entender la crisis que De Gaulle desató en la NATO (p. 21); Le Monde ayuda a vislumbrar cómo se produciría la reunificación de Alemania (p. 
En consideración con los intereses de su polifacético público, integrado por sectores de medio y alto poder adquisitivo, "cosmopolitas e inquietos", ávidos consumidores de información que disfrutaban del lenguaje y formas propuestas por el "new periodism", urbano, de clase media, universitarios con inquietudes intelectuales y profesionales del mundo de la economía, curioso de novedades y necesitado de ser guiado correctamente en la elección de los nuevos insumos estéticos y culturales, la revista contaba con secciones sobre vida moderna, moda, reseñas de libros y tablas de libros y discos "más vendidos", artes, espectáculos y actividades culturales que, sobre todo, marcaban filiaciones de la revista con el Instituto Di Tella, espacio cultural al cual asistía con frecuencia el público lector de Primera Plana. Una revista en síntonía con los prestigiosos signos de la época, novedosa y "modema", crítica con los partidos políticos y liberal en economía, urbana y esteticista, para la "gente linda" que frecuentaba los nuevos circuitos artísticos y de las letras que se identificaban con los itinerarios de las nuevas costumbres de los $60^{56}$ en una "Buenos Aires versátil, sitiada políticamente, $\mathrm{y}$ de intensa vida intelectual". 57

24); Newsweek revela la incréble historia del Krebiozen, una medicina anticancerosa (p. 36), y el nacimiento de un nuevo tipo humano, el 'unisexo' (p. 40). El New York Herald Tribune, en fin, permite que Art Buchwald diga su palabra sobre un tema de moda: el golpe de estado". "Carta al Lector". Primera Plana, n. 169, 22 de marzo de 1966, p. 3.

56 Respecto de la "movida" de los sesenta un privilegiado testigo en brillante síntesis apunta que "Los argentinos [...] indagaban el porvenir en las cartas del Tarot y en el I Ching y firmaban manifiestos en favor de Cuba pero querían vivir, como la Maga, en la ribera izquierda de París. Mientras Cortázar se mantenía lejos, en el paisaje de Buenos Aires asomaban otros soles: los estruendosos happenings y vernisagges del Instituto Di Tella, interrumpidos cada dos por tres por una policía puritana; las canciones para niños de María Elena Walsh - recién desembarcada de París - que inventaban una nueva mitología infantil y se burlaban de los "ejecutivos" en boga; y sobretodo, Borges y Quino." MARTÍNEZ, Tomás Eloy. Viaje al Planeta Quino. Unicornio, Revista Literaria. Mar del Plata, n. 3, diciembre de 1992, p. 10.

57 RÍOS, Ruben. Nota Preliminar, en ROMERO BREST, Jorge. Arte visual en el Di Tella. Aventura memorable en los años 60. Buenos Aires: Emecé, 1992, p. 9. 


\section{Una apuesta por la modernización autoritaria}

Aún cuando Primera Plana se manifestó como una revista heterogénea y abierta a diferentes posiciones $;{ }^{58}$ políticamente, tanto el gobierno de la UCRP como el peronismo tradicional los considero por sus posturas populistas como obstáculos para alcanzar la nación "moderna y desarrollada". Por ello, evaluó como opción válida - en forma sutil y bajo un barniz de "independencia" partidaria - a los nucleamientos políticos de centro derecha, conservadores y a todas aquellas organizaciones y factores de poder comprometidos con el progreso material inspirado en el liberalismo desarrollista y en la modernización económica. Más allá de este posicionamiento, más implícito que manifiesto, la integración y la eficacia de la modernización económica y la necesaria pacificación social y política, eran para el semanario las condiciones básicas para llevar a cabo un programa de crecimiento económico exitoso, ideales considerados superiores a los que pudiera ofrecer una democracia considerada - por gran parte del pensamiento y el espectro político de la época - como "formal". ${ }^{54} \mathrm{El}$ análisis crítico de la realidad política que se desarrollaba en la sección "El País" funcionaba como fuente de información de la actualidad política y a la vez, como una parte de la operación desligitimadora en contra del "arcaico" gobierno de Illia, que era objeto de una crítica mordaz y

${ }^{58}$ En una entrevista, Tomás Eloy Martínez dice al respecto que era posible distinguir las líneas ideológicas que estaban presentes en Primera Plana: liberalconservadora en economía, de avanzada iconoclasta en el tratamiento de los fenómenos culturales y crítica del oficialismo en materia política. Reportaje a Tomás Eloy Martínez, en Página/12, 10 de enero de 1988, p. 15.

59 TERÁN, Oscar. Nuestros años sesenta. La formación de una nueva izquierda intelectual en la Argentina 1956-1966. Buenos Aires: Puntosur, 1991, p. 81-82.

6it En la sección Cartas, a través de una misiva que un lector de la Capital Federal, el señor Oscar Enrique Benedetti envía al director, es posible apreciar la percepción que tenía la revista de la política partidaria: "Señor Director: En varias ocasiones, al comentar cuestiones internas de] MiD [Movimiento de Integración y Desarrollo], el redactor político de esta revista ha mencionado mi nombre, unido al de otros dirigentes seccionales, 'caudillos parroquiales', como con cierto dejo peyorativo se nos denomina. Ello me autoriza a escribirle y me otorga el derecho de que se publique mi carta. Se ha creado una imagen falsa de la situación interna del partido. Por un lado aparecería un gurpo de intelectulaes, doctrinarios y renovadores y por el otro lado un grupo electoralista, resabio de viejas 'trenzas' [compromisos políticos anudados trabajosa y pacientemente] maniobreras, semianalfabetos y profesionales de la política". Primera Plana, n. 161, 7 de diciembre de 1965, p. 80. 
despiada y del que sólo se resaltaban lo que consideraba errores, proponiendo a la opinión pública la eficiencia, supuesta capacidad regeneradora y de orden del general Onganía. Esta posición se puede observar a través del discurso político de Mariano Grondona, ${ }^{61}$ quien al ingresar como redactor especializado a la revista es presentado por Timerman como poseedor de "una honesta y penetrante visión de la misma realidad que a todos nos afecta; $[\ldots]$ con seriedad y rigor casi científico (el doctor Grondona es experto en ciencias políticas), además de una agudísima capacidad de observación periodística"; ${ }^{62}$ mediante esta presentación al lector, el director le otorgaba a priori un alto grado de validez a las opiniones que allí expresaría, predisponiendo positivamente al lector. Su columna política presentará a On-

${ }^{61}$ Su temprana actuación se concentró en la militancia universitaria católica antiperonista del derechista "Movimiento Independiente" de Ia Facultad de Derecho de la Universidad Nacional de Buenos Aires (UNBA), donde se graduó como abogado en 1959 y de la cual es docente de Derecho Politico. También dictó cátedra en la Escuela Superior de Guerra entre 1961 y 1965, en el Instituto de Ciencias Políticas de la Universidad del Salvador (Universidad privada de tendencia católica) y en el "Insituto de Estudios Políticos" de la Universidad de Madrid. Su evolucion de un antiperonismo radical a una posicion negociadora con el neoperonismo vandorista y su inserción en los círculos militares azules se verifica desde su colaboración en el "Comunicado 150 ", que prometía un llamado a elecciones sin proscripción. y a sus orientaciones en cuanto a los parametros del pensamiento político organicista social cristiano. Entonces, exaltaba las virutdes del "comunitarismo", "las sociedades intermedias" y el "desarrollismo" en clave rostowiana. Todo esto le valió para ser designado - durante el gobierno de Guido - como Subsecretario del Ministro del Interior. Su actividad periodística se desplegó como columnista político en los diarios La Nación, El Mundo y Primera Plana - donde también sc ponen de manifiesto su actividad docente y su interés político. Su visión de la necesidad de un rápido crecimiento económico que permitiera fortalecer a la Argentina mediante la vía autoritaria, lo llevó a colaborar con el gobierno de Onganía, en el cual se desempeñó como Asesor General de Política y Planeamiento del Ministerio de Relaciones Exteriores, con jerarquía de Embajador Extraordinario y Plenipotenciario. Actualmente dirige un programa periodístico televisivo de alto "rating" llamado "Hora Clave" donde es crítico con los desbordes autoritarios y los aspectos más crudos de la injusticia social generada por el modelo neoliberal aplicado por el gobierno de Menen. Ha realizado una serie de autocrítias relativizadas por autojustificaciones, sobre su actuación periodistica durante el gobiero de Illia y el Proceso de Reorganización Nacional, definiendo su evolución idcólogica desde el conservadorismo hacia el jiberalismo, siempre dentro de una cosmovisión tomista. 
ganía como el líder extrapartidario ${ }^{63}$ y el conductor excepcional capaz de conducir a la Argentina hacia el destino de grandeza que le aguardaba, ${ }^{64}$ y que, los tradicionales partidos políticos y sus dirigentes, que no alcanzaban a vislumbrar la "Argentina real", le negaban. ${ }^{65}$

Producido el golpe de estado del 28 de junio de 1966, la llegada de Onganía al gobierno coronaría la línea política bajo la cual había surgido Primera Plana: la necesidad de un gobierno fuerte y modernizador que superara las antinomias partidarias que comprometían el futuro de la Nación y estuviera dispuesto a rescatar al país del estancamiento económico y de la indefensión frente al fenómeno de la expansión de los movimientos revolucionarios internacionales. El golpe de estado del 28 de junio de 1966 dio lugar a una edición especial - la del 30 de junio de 1966 -, en la que se toma partido editorialmente y define su postura celebrando el acontecimiento por vía de lo extraordinario pero confirmando su estilo, elaborado con sutilezas y aproximaciones, criticando pero evitando compromisos y definiciones tajantes, legitimando mediante la sugerencia y los implicitos: desde el esfuerzo por informar la confirmación de un hecho ${ }^{66}$ que sus páginas venían tratando como tema del día y mediante la importancia que se le había concedido a Onganía al elegirlo, en reiteradas oportu-

63 Luego de su retiro del servicio activo del Ejército "Más razonable parece pensar en Onganía como en un hombre de reserva institucional, como en una última alternativa de orden y autoridad", Mariano Grondona, Después de Onganía, Primera Plana. n 160, 30 de noviembre de 1965, p. 9.

64 "El país no quiere ni espera un gobierno de pacífica y respetuosa rutina. El país espera un Moisés porque vislumbró la tierra prometida y se encuentra aún muy lejos de ella", Mariano Grondona, La dictadura. Primera Plana, n. 179, 31 de mayo de 1966, p. 11.

${ }^{65}$ Para un análisis pormenorizado de los argumentos de su discurso político ver, TARONCHER PADILLA, Miguel Ángel. Eficiencia y Nación: el discurso legitimador de Mariano Grondona. Trabajo de Investigación de Tercer Ciclo. Valencia: Mimeo., 1997, cap. III, Modernización, Eficiencia, Nación: la Argentina real.

66 "Los hechos ocurrieron y su magnitud - nacional e internacional - puso en marcha, en la misma noche del lunes, esta Edición Especial que ofrecemos ahora a nuestros lectores. Organizada y escrita en 24 horas, ha sido posible en virtud de un triple esfuerzo combinado: el de la redacción de Primera Plana, el de los talleres gráficos que la imprimieron mientras trabajaban en el número siguiente, y el de las agencias y avisadores que permitieron financiar su salida". Carta al lector. Primera Plana. Edición Especial, 30 de junio de 1966, p. 3. 
nidades, como protagonista de sus tapas. ${ }^{67}$ Respecto de las expectativas que abría la nueva etapa será Mariano Grondona quien valorará la situación y ubicará al golpe de estado y al nuevo presidente en el panorama historico-político nacional, el acontecimiento sera percibido como el hito delimitador de dos épocas "el advenimiento del caudillo es la apertura de una nueva etapa, la apuesta vital de una nación en dirección de su horizonte [...]. La etapa que se cierra era segura y sin riesgos: la vida tranquila y declinante de una Nación en retiro. La etapa que comienza está abierta al peligro y a la esperanza: es la vida de una gran Nación cuya vacación termina." 68 Sin embargo, el gobierno de la "Revolución Argentina" auspiciado, junto con otras publicaciones y sectores sociales como solución a la intrincada crisis nacional, clausuró la revista en su edición $N^{\circ} 345$ del 5 de agosto de $1969^{69}$ por ejercer la libertad de prensa que, paradójicamente, le había permitido desempeñar un rol preponderante en la construcción del mito Onganía y en la caída del anterior gobierno constitucional.

En este sentido y como fenómeno cultural de largo alcance, Primera Plana vino a suplir dos requerimientos del momento: el de un espacio editorial semejante al que proponían los semanarios extranjeros de mayor circulación (no sólo con respecto a un tipo de información, sino también a una forma de presentarla a sus consumidores, y particular frente a la tradicional prensa argentina) y el de un vehículo ideológico del proyecto azul triunfante en el campo político-militar. La intervención política de Primera Plana fue un claro emergente de la cultura política de esos años, centrada en la apuesta por un modelo de modernización autoritaria, ${ }^{70}$ el golpe de estado y una intervención del poder militar que asegurase, según el esquema rostowiano, ${ }^{71}$ el desarrollo y el crecimiento como prerequisitos indispensables para poder acceder al tipo de democracias del primer mundo.

67 "Es esta la sexta vez que el teniente general Juan Carlos Onganía ocupa una portada de Primera Plana. La última de cllas en setiembre de 1965, cuando regreso de una gira europea y americana su figura comenzó a trascender fuera de la Argentina" (Ibid.)

68 Por la Nación, Primera Plana, op. cit., p. 3.

69 La revista es clausurada por el Poder Ejecutivo Nacional debido a que la edición de esa semana publicaba las desavenencias entre el Presidente Onganía y el Comandante en Jefe del Ejército, General Alejandro Agustín Lanusse.

${ }^{70}$ O'Donnell, op. cit.

71 ROSTOW, W. W. Las etapas del crecimiento económico. Un manifiesto anticomunista. México: Fondo de Cultura Económica, 1962. Introducción. 
Primera Plana fue el espacio privilegiado en el cual se reunieron y retroalimentaron nuevos emprendimientos editoriales y la modernización cultural. En ella confluían el periodismo (en cuanto relato del acontecer inmediato), la novela (en tanto estrategias de diseño informativo) y las ciencias sociales, como miradas analíticas y modelos de aproximación a la cambiante realidad del mundo moderno. Como un ejemplo del "New Periodism" en Argentina, todos estos elementos construyeron un periodismo diferente al tradicional, versátil en cuanto a điseño, tratamiento y presentación de la información, permeable a las nuevas disciplinas y modas de una sociedad que transformaba sus antiguos moldes y que pretendía emerger del atolladero político mediante la instauración de un gobierno autoritario. 